\title{
Natural history of coral-algae competition across a gradient of human activity in the Line Islands
}

\author{
Katie L. Barott ${ }^{1, *}$, Gareth J. Williams ${ }^{2}$, Mark J. A. Vermeij ${ }^{3,4}$, Jill Harris ${ }^{2}$, \\ Jennifer E. Smith ${ }^{2}$, Forest L. Rohwer ${ }^{1}$, Stuart A. Sandin ${ }^{2}$ \\ ${ }^{1}$ Biology Department, San Diego State University, 5500 Campanile Drive, San Diego, California 92182, USA \\ ${ }^{2}$ Center for Marine Biodiversity and Conservation, Scripps Institution of Oceanography, University of California San Diego, \\ 9500 Gilman Drive, La Jolla, California 92083, USA \\ ${ }^{3}$ Caribbean Research and Management of Biodiversity (CARMABI), Piscaderabaai z/n, PO Box 2090, Willemstad, Curacao \\ ${ }^{4}$ Aquatic Microbiology, Institute for Biodiversity and Ecosystem Dynamics, University of Amsterdam, Science Park 700, \\ 1098 XH Amsterdam, The Netherlands
}

\begin{abstract}
Competition between corals and benthic algae is prevalent on coral reefs worldwide and has the potential to influence the structure of the reef benthos. Human activities may influence the outcome of these interactions by favoring algae to become the superior competitor, and this type of change in competitive dynamics is a potential mechanism driving coral-algal phase shifts. Here we surveyed the types and outcomes of coral interactions with benthic algae in the Line Islands of the Central Pacific. Islands ranged from nearly pristine to heavily fished. We observed major differences in the dominant groups of algae interacting with corals between sites, and the outcomes of coral-algal interactions varied across reefs on the different islands. Corals were generally better competitors against crustose coralline algae regardless of location, and were superior competitors against turf algae on reefs surrounding uninhabited islands. On reefs surrounding inhabited islands, however, turf algae were generally the superior competitors. When corals were broken down by size class, we found that the smallest and the largest coral colonies were the best competitors against algae; the former successfully fought off algae while being completely surrounded, and the latter generally avoided algal overgrowth by growing up above the benthos. Our data suggest that human disruption of the reef ecosystem may lead to a building pattern of competitive disadvantage for corals against encroaching algae, particularly turf algae, potentially initiating a transition towards algal dominance.
\end{abstract}

KEY WORDS: Crustose coralline algae - Turf algae · Macroalgae $\cdot$ Coral reef $\cdot$ Interaction $\cdot$ Line Islands

Resale or republication not permitted without written consent of the publisher

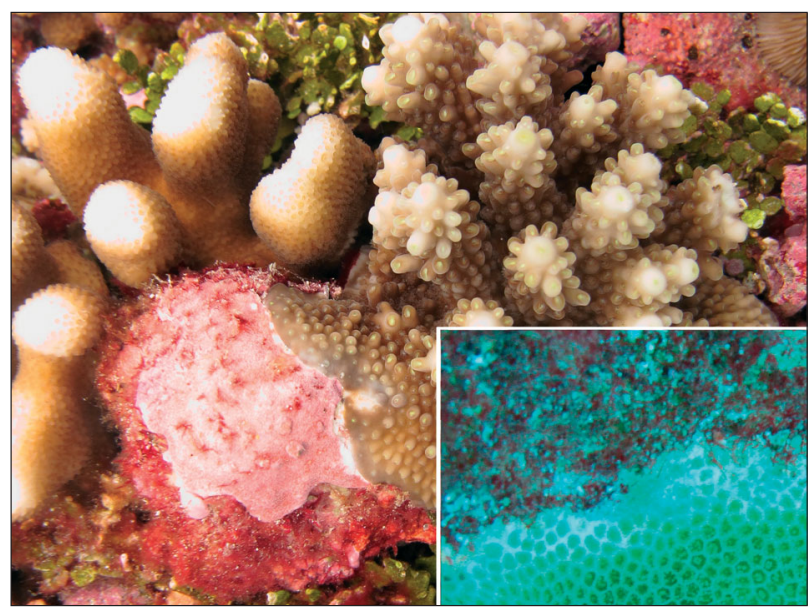

Competition between corals and algae is common on healthy reefs, but certain types of algae (e.g. turf algae, inset) are more harmful to corals than others (e.g. crustose coralline algae, main photo), and these negative effects can be exacerbated by human activities.

Photo: Katie Barott

\section{INTRODUCTION}

Coral reefs are areas of intense competition between sessile benthic organisms. Sufficient access to space and light is crucial for survival on the reef, and the ability to establish, maintain, and extend territory (i.e. to outcompete fellow benthic organisms) can affect the composition, size, and distribution of organisms on the benthos (Lang \& Chornesky 1990). Corals and benthic algae are 2 of the main groups that com- 
pete for space on a coral reef, and interspecific interactions can have major effects on the growth and reproduction of benthic competitors (Chadwick \& Morrow 2011). Corals, for example, can inhibit the growth of algae, with the strength of inhibition determined by species identity and environmental conditions (De Ruyter van Steveninck et al. 1988, Nugues \& Bak 2006, Titlyanov et al. 2007, Vermeij et al. 2010). The ability of corals to fight off their algal competitors becomes increasingly important in the face of local stressors (eutrophication, sedimentation, fishing) and global climate change (rising sea surface temperature, ocean acidification), particularly since algae are becoming more dominant on coral reefs around the world (Hughes 1994, Hoegh-Guldberg 1999, McCook 1999, Hughes et al. 2007).

The effects of algae on corals can vary widely by the type of alga involved in the competition. Macroalgae, for example, have a range of detrimental effects on corals, which include inhibition of coral recruitment, growth, and fecundity (Tanner 1997, River \& Edmunds 2001, Titlyanov et al. 2007, Birrell et al. 2008, Foster et al. 2008, Vermeij et al. 2009). Many macroalgae produce secondary metabolites (i.e. allelochemicals) that cause some of these negative effects on different coral life stages (Gross 2003, Rasher \& Hay 2010, Paul et al. 2011, Rasher et al. 2011). Turf algae, a diverse assemblage of filamentous algae, also have a variety of effects on corals. Turf algae can lead to hypoxia along competitive borders with corals (Barott et al. 2009, 2012), cause tissue damage and bleaching along the coral border (Barott et al. 2009, Haas et al. 2010), lower coral fecundity (Foster et al. 2008), and can inhibit coral recruitment (Birrell et al. 2005, 2008, Hughes et al. 2007, Arnold et al. 2010). Competition with turf or macroalgae also alters the microbial communities associated with corals, with turf algae in particular leading to an increase in potential pathogens on corals (Barott et al. 2012). Some algal assemblages, however, have little effect on neighboring corals (McCook 2001) or on coral recruitment (Birrell et al. 2008), indicating that the composition of the turf community likely plays an important role in the interaction with corals. Turf algae are among the most abundant algal competitors that corals face (Barott et al. 2009, 2012, Haas et al. 2010), and as such, likely play an important role in initiating algal phase shifts on disturbed coral reefs. Crustose coralline algae (CCA), in contrast, are generally less detrimental to corals than are other types of algae (Barott et al. 2009, 2012, Vermeij et al. 2010). CCA can even be beneficial for corals by providing settlement cues and substrate for coral larvae (Morse et al. 1988, Negri et al. 2001, Price 2010) while limiting colonization of some types of potentially harmful macroalgae (Vermeij et al. 2011).

Changing environmental factors such as eutrophication, reduced herbivory, or ocean acidification can shift the dynamics of interactions on the reef. For example, decreased herbivory leads to a decrease in CCA abundance (Burkepile \& Hay 2006), an increase in turf and macroalgae (Miller 1998), and a shift towards algal dominance (Hughes et al. 2007), whereas high herbivory is associated with more CCA and less turf and macroalgae (Littler et al. 2006, Sotka \& Hay 2009, Burkepile \& Hay 2009). The types of herbivores present affect the distribution of algae on the reef (Burkepile \& Hay 2008), and selective removal of urchins versus herbivorous fish, for example, can have a major impact on the types of algae along coral borders (Sandin \& McNamara 2012). Nutrient enrichment can also alter competitive outcomes by both inhibiting coral growth and stimulating algal growth, although the effect of nutrients tends to be less than that of herbivores (McCook 1999, Jompa \& McCook 2002, Burkepile \& Hay 2006, 2009, Sotka \& Hay 2009; but see Vermeij et al. 2010). Ocean acidification (i.e. $\mathrm{CO}_{2}$ enrichment) can also increase macroalgal damage on corals (Diaz Pulido et al. 2011) and inhibit the calcification of CCA (Anthony et al. 2008), potentially leading to a competitive advantage of turf and macroalgae over both corals and CCA.

Overall, local to global anthropogenic disturbances appear to be shifting the competitive advantage towards turf and macroalgal dominance with the concomitant loss of reef-accreting calcifiers such as corals and CCA. Here we surveyed the abundance, composition, and apparent outcome of different types of coral-algae competitive interactions on coral reefs in the Line Islands of the Central Pacific. Survey sites included reefs surrounding 2 nearly pristine uninhabited islands, as well as reefs experiencing a gradient of human activity, inorganic and organic nutrient regimes, and microbial communities (Dinsdale et al. 2008, Sandin et al. 2008).

\section{MATERIALS AND METHODS}

\section{Site descriptions}

This investigation was conducted during an expedition to the Line Islands in October and November 2010. The islands visited for this study (followed by the abbreviations used throughout the text) inclu- 
ded Kingman Reef $\left(\mathrm{KIN}_{i} 6.390^{\circ} \mathrm{N}, 162.360^{\circ} \mathrm{W}\right)$, Teraina (TER; $\left.4.686^{\circ} \mathrm{N}, 160.420^{\circ} \mathrm{W}\right)$, Tabuaeran $\left(\mathrm{TAB}_{i} 3.825^{\circ} \mathrm{N}, 162.349^{\circ} \mathrm{W}\right)$, Kiritimati $\left(\mathrm{KIR}_{i} 2.008^{\circ} \mathrm{N}\right.$, $157.489^{\circ} \mathrm{W}$ ), and Jarvis $\left(\mathrm{JAR}_{i} 0.369^{\circ} \mathrm{S}, 160.008^{\circ} \mathrm{W}\right.$; Fig. 1). Surveys were grouped by the region within each island and are labeled by island abbreviation and location within the island (e.g. N: north, S: south). Kingman and Jarvis are uninhabited USA protectorates that are managed by the US Fish and Wildlife Service as part of the Pacific Remote Islands Marine National Monument. Teraina (also known as Washington), Tabuaeran (Fanning), and Kiritimati (Christmas) belong to the Republic of Kiribati and are inhabited (approximately 1000, 3000, and 10000 people per island, respectively; DeMartini et al. 2008, Sandin et al. 2008). The reefs of Kiritimati and Tabuaeran contain greater abundances of fleshy algae, bacteria, and viruses (Dinsdale et al. 2008) than the reefs of the other islands studied, while the reefs of Kingman and Jarvis have a greater abundance of predatory fish and reef-building corals and CCA (Sandin et al. 2008, Williams et al. 2011). Tabuaeran, Kiritimati, and Jarvis have higher inorganic nutrient concentrations in the water column due to their location within the equatorial countercurrent with concomitant elevation of nearshore upwelling (Sandin et al. 2008). All surveys for this study were conducted on the forereef with the exception of Kingman, where surveys were conducted on a patch reef in the large lagoon.

\section{Benthic cover}

The composition of the benthos was determined using the photoquadrat method (Preskitt et al. 2004). At each site, 2 transects ( $25 \mathrm{~m}$ each) were deployed at a constant depth of 10 to $12 \mathrm{~m}$. A total of 5 quadrats placed at $5 \mathrm{~m}$ intervals were photographed per transect using a Canon G9 camera connected to a quadpod and frame (0.63 $\mathrm{m}^{2}$ total area within each image). Image analysis of the photoquads was completed using Photogrid 1.0 (www2.hawaii.edu/ cbird/index. $\mathrm{html}$ ). A total of 100 points were placed in a stratified random design over each image, with the substrate under each point identified to the finest resolution possible (genus for corals, macroalgae, and invertebrates when possible, and functional group for turf algae and CCA). When no biological cover was noted under a point, the non-biological substrate (e.g. sand) was recorded. Benthic cover data were complemented from comparable collections made in May 2010 by scientists from the NOAA Coral Reef Ecosystem Division using similar methods (Brainard et al. 2005).



Fig. 1. Surveyed islands. Triangles indicate survey locations. Maps were generated using ArcGIS 


\section{Surveys of coral-algal interactions}

In order to quantify the abundance of coral-algal interactions, a line point intercept survey approach was used as previously described (Barott et al. 2009). All surveys were conducted at a constant depth of $10 \mathrm{~m}$ along a $10 \mathrm{~m}$ transect line, and at least 2 transects were conducted per site. For each coral colony intercepting the transect line, the identity (to genus level) and maximal colony diameter were recorded. Any alga in contact with the coral colony was identified to genus for macroalgae or functional group for CCA and turf algae. The proportion of the coral colony's edge involved in each type of coral-algal interaction was estimated by eye (3 different divers conducted all surveys), and the putative outcome of each interaction was recorded. Three outcomes of interactions were defined as: coral damaging algae, algae damaging coral, and apparently neutral (Fig. 2). Due to natural variations in benthic community structure and species distributions across sites and islands, the number of specific outcomes encountered along any given transect varied and could not be standardized, and thus the statistical power varied for each interaction type. It is important to note that these assessments provide a snapshot in time for each interaction, and the actual direction of overgrowth for each interaction cannot be determined from this type of survey.

\section{Statistical analyses}

Statistical analyses were completed using $\mathrm{R}$ ( R Development Core Team 2010) unless otherwise stated. In order to test whether the proportion of algal types bordering corals was purely a function of their relative abundance on the reef benthos at the site, we used a tailored resampling approach to account for the non-independence of multinomial, percent cover data. Consider, for example, a set of 4-dimensional data representing the benthic types in a proportional sample (e.g. coral edge or reef benthos). As exhaustive proportions of a whole, these data can be visualized in a 3-dimensional manner; the fourth variable is strictly dependent on the values of the other 3 , as 1 minus the sum of these 3 proportions. Each replicate then is 1 point in this 3 -dimensional space. When comparing the distribution of replicates across 2 groups, our goal was thus to identify whether the 3dimensional clouds of points overlapped appreciably or were more distinct than expected by chance (i.e. limited overlap in dispersion around each group's centroid).

To formally test the null hypothesis that the 2 groups did not differ (i.e. there was sufficient overlap between the 2 groups to suggest that the edge and benthos algal communities did not differ) we employed a resampling approach to estimate the probability of group membership affecting the distribution


Fig. 2. Coral-algal interaction examples. Left column, coral damaging algae (top: CCA versus Acropora sp., bottom: CCA versus Porites sp.); middle column, neutral (top: CCA versus Acropora sp., bottom: turf algae versus Porites sp.); right column, algae damaging coral (top: CCA versus Porites sp., bottom: turf algae versus Porites sp.). Arrows indicate areas of tissue damage 
of distances from each group's centroid (analogous to analysis of variance logic). The null distribution of deviations was generated using a resampling procedure in which group membership was randomized across the total set of replicates (multinomial estimates from each group combined), while maintaining the same sample size per group. The procedure was repeated 10000 times, and a distribution of Euclidean distances between the centroids of these randomized groups was created. The null distribution allows us to test whether group-specific centroids are equivalent by comparing the observed distance between centroids to the null distribution. When the observed difference exceeded the 95th percentile of the null distribution of distances, we rejected the null hypothesis (setting our threshold for significance to 0.05), indicating that the coral edge and reef benthos algal communities differed.

In order to determine whether the proportion of coral borders with 'no algae' differed by size class, we used a non-parametric Kruskal-Wallis test with subsequent Dunn's procedure for pairwise comparisons, and applied a Bonferroni alpha of $p=0.02$ to compensate for the multiple comparisons. We further determined whether the number of colonies with a greater proportion of their edge winning to algae versus losing to algae were statistically different from random (0.5) using a 2-tailed binomial distribution test. The differences between sites based upon the algal proportions and outcomes along coral borders (e.g. percent coral border losing to turf algae) were determined using the Bray-Curtis index (vegdist in the package Vegan). A non-metric multidimensional scaling (nMDS) ordination was performed on the Bray-Curtis similarity matrix to visualize the separation of the sites based on coral-algal competition (monoMDS in the package Vegan), and statistical clustering of sites was determined using a similarity profile test (simprof in the package Clustsig).

\section{RESULTS}

\section{Composition of the reef benthos}

Hard coral cover was greatest at KIN (67\%), JARW $(58 \%)$, and KIR-S $(48 \%)$, and lowest at TER-W $(9 \%)$ and JAR-N (11\%) (Table 1). CCA cover was highest at TER-W (45\%), followed by KIR-S (33\%) and TAB-S (30\%) (Table 1). CCA was lowest at KIR$\mathrm{N}(3 \%)$ and JAR-N $(8 \%)$, the 2 sites that also had the greatest abundance of turf algae (59 and $78 \%$ of the benthos, respectively) (Table 1). Turf algae cover was
Table 1. Composition of the reef benthos and organisms along the coral edge in percentage of cover and edge, respectively, at each site. Sites are listed by decreasing hard coral cover. See 'Materials and methods' for a description of the sites. CCA: crustose coralline algae, NA: not applicable

\begin{tabular}{|c|c|c|c|c|c|c|c|}
\hline Site & $\begin{array}{l}\text { Hard } \\
\text { coral }\end{array}$ & $\mathrm{CCA}$ & $\begin{array}{l}\text { Hali- } \\
\text { meda }\end{array}$ & $\begin{array}{c}\text { Fleshy } \\
\text { macro- } \\
\text { algae }\end{array}$ & $\begin{array}{c}\text { Turf } \\
\text { algae }\end{array}$ & Other & $\begin{array}{l}r \text { No } \\
\text { algae }\end{array}$ \\
\hline \multicolumn{8}{|l|}{ Benthos } \\
\hline KIN & 67 & 11 & 3 & 2 & 13 & 4 & NA \\
\hline JAR-W & 58 & 12 & 0 & 7 & 22 & 1 & NA \\
\hline KIR-S & 48 & 33 & 1 & 0 & 8 & 9 & NA \\
\hline TAB-W & 37 & 20 & 15 & 2 & 25 & 0 & NA \\
\hline KIR-N & 24 & 3 & 8 & 0 & 59 & 7 & NA \\
\hline TAB-S & 23 & 30 & 35 & 9 & 4 & 0 & NA \\
\hline TER-N & 21 & 22 & 17 & 15 & 20 & 5 & NA \\
\hline JAR-N & 11 & 8 & 0 & 2 & 78 & 0 & NA \\
\hline TER-W & 9 & 45 & 7 & 2 & 26 & 12 & NA \\
\hline \multicolumn{8}{|l|}{ Edge } \\
\hline KIN & NA & 34 & 4 & 1 & 13 & 0 & 47 \\
\hline JAR-W & NA & 7 & 0 & 1 & 34 & 0 & 57 \\
\hline KIR-S & NA & 28 & 1 & 3 & 37 & 0 & 31 \\
\hline TAB-W & NA & 17 & 8 & 1 & 13 & 0 & 61 \\
\hline KIR-N & NA & 0 & 0 & 12 & 83 & 0 & 5 \\
\hline TAB-S & NA & 40 & 19 & 3 & 20 & 0 & 18 \\
\hline TER-N & NA & 21 & 20 & 6 & 36 & 0 & 16 \\
\hline JAR-N & NA & 16 & 0 & 1 & 74 & 0 & 8 \\
\hline TER-W & NA & 16 & 2 & 6 & 46 & 0 & 31 \\
\hline
\end{tabular}

lowest at TAB-S $(4 \%)$, which had the highest abundance of macroalgae ( $43 \%$, primarily calcifying Halimeda spp.). Macroalgal cover was also high at TERN (32\%; Table 1), and was about half calcareous Halimeda spp. and half fleshy macroalgae.

\section{Composition of algae interacting with corals}

The types of algae that corals were interacting with varied by site. KIR-N and JAR-N had the greatest proportion of the coral edge interacting with turf algae ( $>75 \%$ of each coral border), followed by TER-N\&W, KIR-S, and JAR-W (34-46\%) (Table 1). The highest amount of edge occupied by CCA occurred at KIN and TAB-S (35-40\%; Table 1). Halimeda spp. were most abundant along the coral edge at TER-N and both TAB sites (8-20\%; Table 1). KIN, TAB-W, and JAR-W had the greatest proportion of coral edges that were not interacting with any algae $(47-61 \%)$.

At all sites, with the exception of TAB-W, the abundance and composition of algae along the coral edge was not purely a function of the relative abundance of the algae found on the benthos (Fig. 3, Table S1 in the supplement at www.int-res.com/articles/suppl/ m460p001_supp.pdf). For example, coral borders at 
KIN were comprised of a greater abundance of CCA than would be expected by chance alone based on the relative abundance of CCA on Kingman's benthos. Similarly, TER-W and KIR-S had less CCA bordering corals than expected by chance alone (Fig. 3). These 2 sites also had a greater proportion of turf algae interacting with corals than expected by chance alone; this was also true for JAR-W, TER-N, and TAB-S. In addition, TAB-S had fewer macroalgae, particularly Halimeda spp., interacting with corals than expected by chance alone given the relative abundance of macroalgae at the site (Fig. 3).

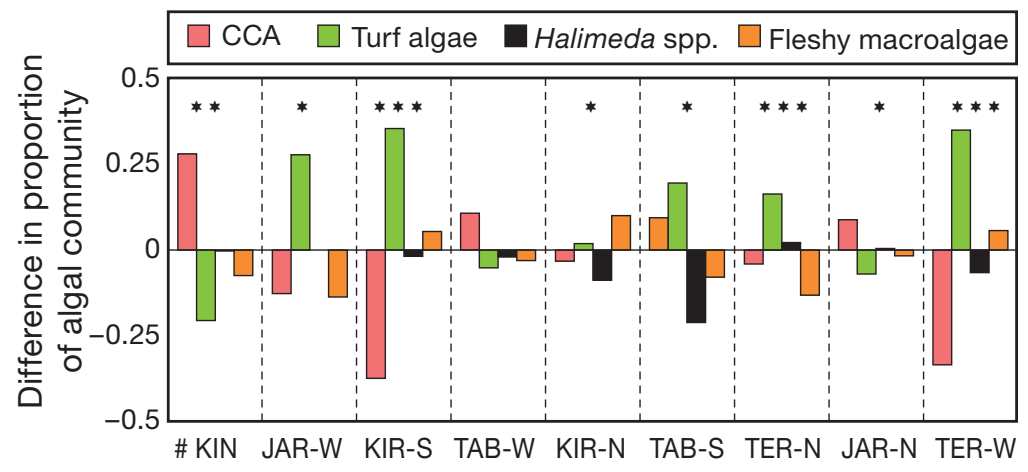

Fig. 3. Difference between the composition of coral-algal interactions (i.e. algae along coral borders) and algal composition of the benthos. Greater than zero indicates enriched along the coral border. Sites are listed by decreasing hard coral cover. See 'Materials and methods' for a description of the sites. \#: lagoon habitat, CCA: crustose coralline algae. ${ }^{*} \mathrm{p}<0.05$, ${ }^{* *} \mathrm{p}<0.01,{ }^{* * *} \mathrm{p}<0.001$

\section{Coral colony size and algal interaction outcomes}

Both of the TER sites and KIR-S were dominated by small corals $<40 \mathrm{~cm}$ in diameter (Fig. S1 in the supplement). KIR-S differed from TER in that there were a greater number of corals per meter; this site had high coral cover (Table 1), but all were small to midsize coral colonies (Fig. S1 in the supplement). KIN and TAB had the largest coral colonies present, with many corals reaching over $1 \mathrm{~m}$ in diameter, primarily Porites spp. at KIN and Acropora spp. at TAB (Figs. S1 \& S2 in the supplement). JAR-N had a low density of mostly small coral colonies $(<20 \mathrm{~cm})$, while JAR-W had a high density of coral colonies, including many large corals $>80 \mathrm{~cm}$ that were almost entirely Montipora spp. (Figs. S1 \& S2 in the supplement).

The total proportions of coral colony borders that were not in contact with algae ('no algae') differed significantly across coral size classes (Kruskal-Wallis, $H=87.96$, df $=5, \mathrm{p}<0.0001)$. For example, 5 and $10 \mathrm{~cm}$ classes, while not significantly different from each other, had less 'no algae' (i.e. more algae) than all larger size classes (Dunn's, p $<0.0001$ and $\mathrm{p}<$ 0.0009 , respectively). The $20 \mathrm{~cm}$ class had less 'no algae' than the 2 largest classes $(80$ and $>80 \mathrm{~cm}$; $\mathrm{p}=$ 0.0064 and $p=0.0008$, respectively), but did not differ from the $40 \mathrm{~cm}$ class. These 2 largest classes (80 and $>80 \mathrm{~cm}$ ) were not significantly different, with $\sim 30 \%$ of each colony's border in contact with algae, and these classes were mainly composed of the genera Acropora, Montipora, and Porites. In contrast, the smallest colonies $(<10 \mathrm{~cm}$ in diameter) were almost completely surrounded by algae $(\sim 80 \%$ of the perimeter, Fig. 4a) and were dominated by the genera Pocillopora, Montipora, and Porites.
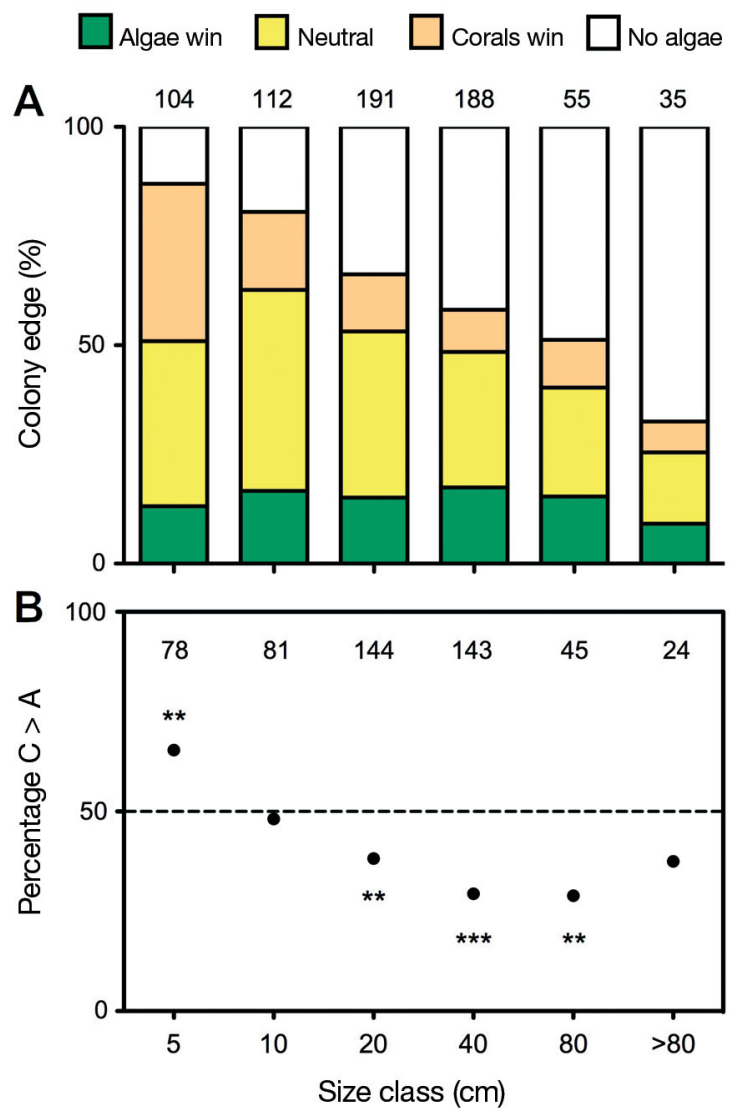

Fig. 4. Coral-algal interactions by coral size class. (A) Algal competition outcomes by size class. Numbers above columns indicate the number of colonies observed. (B). Percentage of coral colonies where corals are winning against algae $(\mathrm{C}>\mathrm{A})$ along a greater proportion of the colony edge than they are losing to algae. Numbers indicate the number of colonies included in the analysis (i.e. colonies with at least 1 non-neutral algal interaction). ${ }^{* *} \mathrm{p}<0.01,{ }^{* * *} \mathrm{p}<0.001$ 
The outcome of coral-algal interactions varied depending on coral size class. The smallest coral colonies $(<5 \mathrm{~cm})$ were the only coral size class to have a greater proportion of their border winning against algae than losing ( $p<0.001$, Fig. 4b). A total of 104 corals fell into this class, and included 12 different genera. Both the $10 \mathrm{~cm}$ and $>80 \mathrm{~cm}$ size classes (112 individuals from 12 genera and 35 individuals from 6 genera, respectively) showed no bias in the proportions of their edge winning and losing to algal competition (Fig. 4b), indicating that for these coral classes, the 2 are equal. In contrast, mid-sized coral colonies $(20,40$, and $80 \mathrm{~cm}$; including 434 individuals from 16 genera) lost a greater proportion of their border to algae than they won (Fig. 4b). Each size class included a wide variety of coral genera and morphologies, indicating that the patterns observed were size- and not necessarily species- or morphology-dependent.

\section{Coral-algal interaction outcomes by site}

Coral-algal interaction outcomes varied by site. Algae were winning the greatest proportion of competitive interactions along the coral edge at KIRN\&S, TAB-S, and TER-W (Fig. 5a). In contrast, JAR$\mathrm{N}$ had the greatest proportion of corals winning versus losing along the coral edges (Fig. 5a). Within a site, coral-algal interaction outcomes varied by the type of algae. Corals tended to be superior competitors (i.e. coral winning more of the competitive edge than algae) against CCA (Fig. 5b). However, when corals were interacting with turf algae, the only site where corals were superior competitors was JAR-N ( $p<0.05$ ) (Fig. 5c). Competitive outcomes between corals and turf algae did not differ at KIN, JAR-W, KIR-N, or TER-N, but corals were losing a greater proportion of competitive interactions along their border to turf algae at KIR-S, TER-W, and TAB-S\&W ( $p<0.01$; Fig. 5c).

A similarity profile test indicated that the sites formed 4 significant clusters based upon the types and outcomes of coral-algal interactions (Fig. 6). The first cluster included KIN, TAB-W, and JAR-W, and an nMDS ordination indicated a correlation of these sites with a high proportion of edge not in contact with algae. JAR-N and KIR-N formed another cluster, correlated with a high proportion of turf algae along the coral edges at these sites. While forming a single cluster, however, JAR-N appeared to be correlated with corals mostly winning against turf algae, while at KIR-N they were losing (Fig. 6).
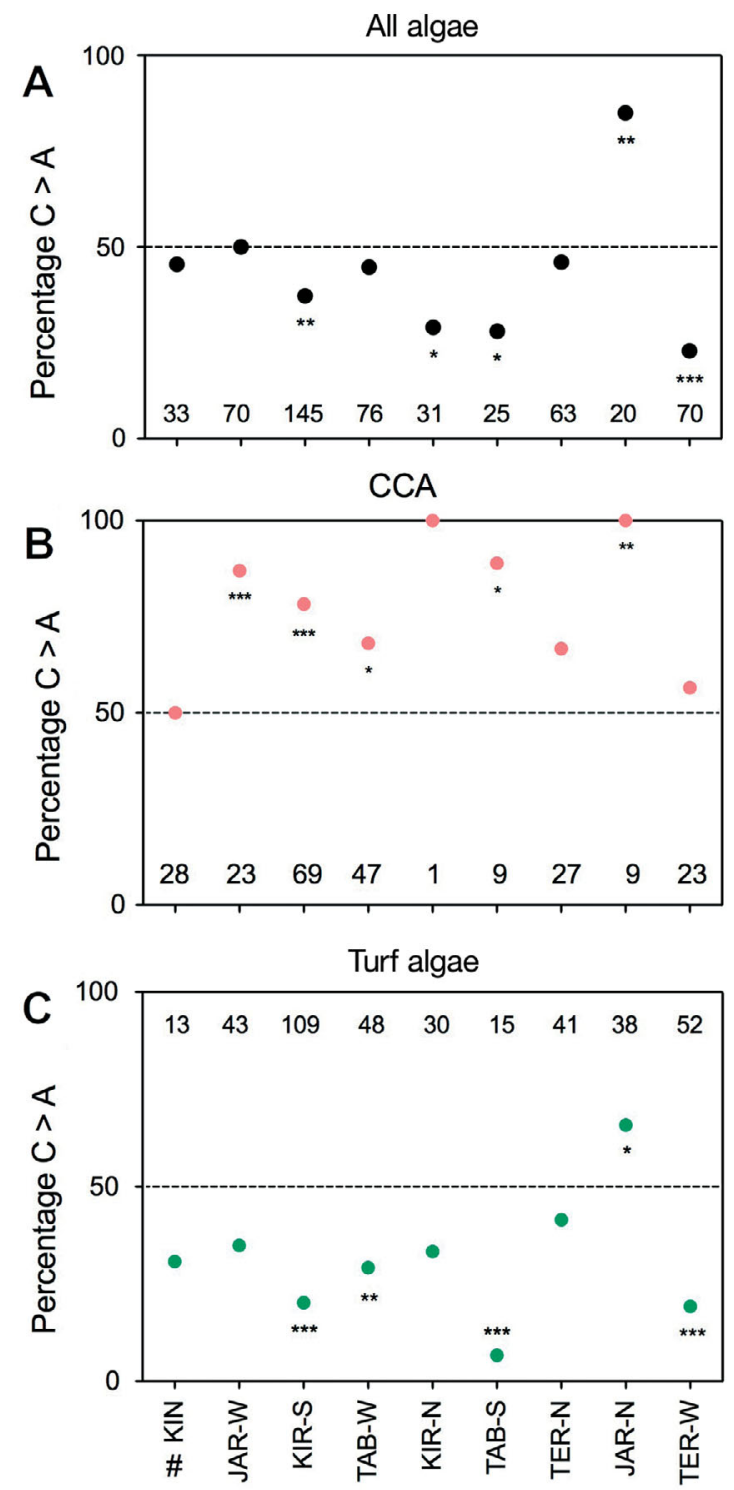

Fig. 5. Percentage of coral colonies where corals are winning against (A) all algae types, (B) crustose coralline algae (CCA), or (C) turf algae, along a greater proportion of the colony edge than they are losing to that type of alga. Numbers indicate the number of colonies included in the analysis (i.e. colonies with at least 1 non-neutral algal interaction). Sites are listed by decreasing hard coral cover. See 'Materials and methods' for a description of the sites. ${ }^{*} \mathrm{p}<0.05,{ }^{* *} \mathrm{p}<0.01,{ }^{* * *} \mathrm{p}<0.001$, \#: lagoon habitat

TER-N and TAB-S clustered together, and were likely correlated with a high proportion of the coral edges interacting with Halimeda spp. (calcified macroalgae). TER-W and KIR-S also clustered together, and were correlated with a high proportion of the coral edge interacting with other types of fleshy algae (e.g. Caulerpa spp., Lobophora spp.; Fig. 6). The clustering of the different sites by 


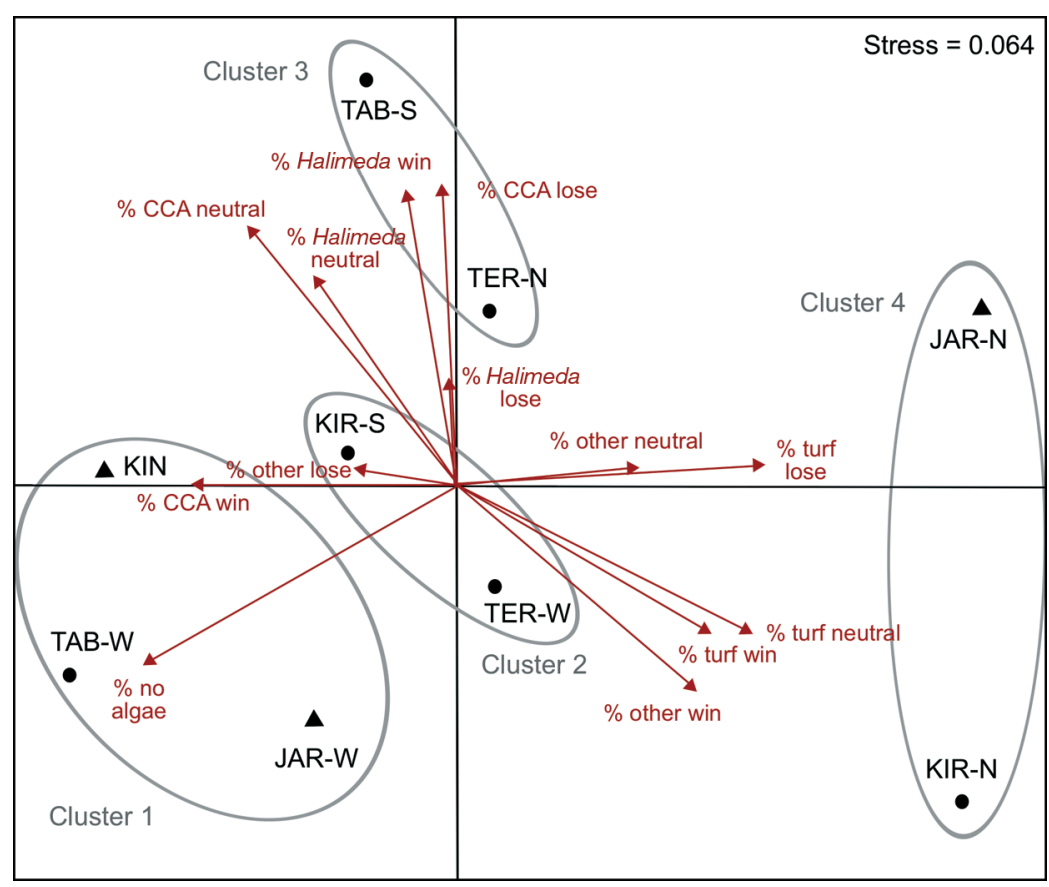

Fig. 6. Non-metric multidimensional scaling plot of outcomes of coral-algal interactions by site, using the Bray-Curtis similarity index. See 'Materials and methods' for a description of the sites. Circles: inhabited islands; triangles: uninhabited islands, CCA: crustose coralline algae. Clusters were determined by a similarity profile (SIMPROF) test $(\alpha=0.05)$

coral-algal competitive types and outcomes did not appear to be purely a function of the relative abundance and composition of the coral genera present at the sites, since sites with different dominant coral genera (e.g. JAR-W, KIN, and TAB-W; Fig. S2 in the supplement) still clustered together based on competitive outcomes (Fig. 6).

\section{DISCUSSION}

\section{Coral colony size and possible strategies for competition with benthic algae}

Small coral colonies were typically surrounded by algal competitors along most of their perimeter, yet these small colonies tended to be better competitors against algae. Partial coral mortality most often occurs from bottom-related processes (e.g. algal competition) for all coral size classes, and these types of partial mortality events often result in total mortality for small colonies (Jackson 1977, Meesters et al. 1996). It is possible then that small colonies that were not good competitors against algae may not have been observed due to their high rates of mortality, leaving only the small colonies that were the competitively dominant survivors to be observed. This dynamic suggests that size escape may be an important strategy employed by corals for surviving algal competition (Jackson 1977, Meesters et al. 1996), making growth a particularly important investment for small colonies. It is important to note that apparently neutral interactions with algae likely require an energetic investment to keep the interaction from becoming a 'losing' interaction for the coral. This investment usually requires an energetic tradeoff, however, indicated by observations that young corals of the smallest size classes grow quickly but are not reproductively active (Babcock 1991, Soong \& Lang 1992, Soong 1993), saving their limited resources to grow and defend their borders. This strategy may explain why the small colonies observed here were mostly winning against algae, since much of their available energy is likely spent on growth and competition.

Mid-sized corals, in contrast, lost to algae more than they won. It is likely that these adult coral colonies invest less energy into fighting off algae at their borders, particularly since they are likely to be at a reproductive age and thus may allocate a significant amount of energy towards reproduction (Babcock 1991, Soong \& Lang 1992, Soong 1993). In addition, small losses along the colony edge are not as significant for these colonies, since a loss of $1 \mathrm{~cm}$ to an algal competitor is only a small proportion of the entire colony. While it is still important to maintain tissue health and growth along the colony edge, less of the entire colony's energy resources are likely to be diverted to this area as more energy is invested in reproduction. Competition and growth are not sacrificed, however, and previous observations that the edges of larger colonies contain few to no reproductive polyps (Soong \& Lang 1992, Foster et al. 2008) suggest that the energy of these polyps is allocated towards growth and competition in lieu of reproduction. If reproduction does affect competition, the time of year these types of surveys are done may influence the outcomes observed along coral borders with algae, since many corals reproduce on seasonal cycles. Due to the single time-point nature of the current study, this hypothesis remains to be tested. 
The largest coral colonies observed (>80 cm), like small colonies, appeared to be better competitors against algae than their mid-sized counterparts. However, in contrast to small colonies, the proportion of the perimeter of large colonies interacting with algae was low ( 30\%; Fig. 4a). Large corals appeared to use an 'escape in height' strategy (Meesters et al. 1996), growing up above the surrounding benthos and avoiding algal competition altogether. Since relatively little of the colony border was interacting with algae, less energy would be needed to defend against the algae than if the entire perimeter were in contact with algae, as it is for smaller colonies. Furthermore, the area from which a large coral colony can draw energy (e.g. from symbiotic zooxanthellae photosynthesis, Yellowlees et al. 2008; or heterotrophic feeding, Houlbrèque \& Ferrier-Pagès 2009) is much greater than for a small colony, since the area of a colony increases much more rapidly than the perimeter. Therefore, large colonies likely have more energy to draw from that can be used to fight algae along the border, while still having enough energy to invest in reproduction.

\section{Coral-algal interactions change with human habitation}

The composition and outcome of coral-algal competition varied depending on the site. In general, coral competition with CCA did not appear to be detrimental for corals, regardless of the site or level of human habitation. On the other hand, corals appeared to lose more often to turf algae on reefs surrounding inhabited islands, while being equal or superior on reefs surrounding uninhabited islands. Corals experiencing local human influences may be weaker competitors due to an increased abundance of potentially pathogenic bacteria and a higher prevalence of certain coral diseases (Dinsdale et al. 2008). In addition, algae may become better competitors on reefs surrounding inhabited islands due to increased inorganic nutrient concentrations that may increase fleshy algal growth or increase the abundance of pathogenic bacteria. On reefs surrounding inhabited islands, increases in the success of turf algae over corals may be a result of a shift in reef fish community structure due to fishing pressure (DeMartini et al. 2008, Sandin et al. 2008, Ruttenberg et al. 2011). These changes in the fish community likely alter herbivore consumption rates, and may allow turf algae to increase in abundance and/or change the composition of the turf assemblage entirely. These changes may affect the types of associated microbes, production of dissolved organic carbon (Haas et al. 2011), or allelochemicals by the turf algae, possibly increasing the release of compounds or microbes that are detrimental to corals (Smith et al. 2006, Rasher \& Hay 2010, Barott et al. 2012) and may therefore affect the outcomes of coral-algal competition over time.

Differences in latitude and biogeography (e.g. nutrient levels) are not likely the driving factor for changes in coral-algal competition outcomes observed here. Jarvis, for example, experiences significant upwelling of nutrients and has a high abundance of coral interactions with turf algae, yet the corals at Jarvis were winning the majority of the competitive interactions against turf algae. This occurred despite the difference in coral cover between the 2 sites (JARN, $8 \%$; JAR-W, $58 \%$ ), which may be the result of differences in upwelling (highest at JAR-W; Gove et al. 2006) and/or a past bleaching event on JAR-N due to high sea surface temperature anomalies which occurred in 1998 (Gove et al. 2006), 2003 (Gove et al. 2006, Miller et al. 2008), and 2009 (J. Gove pers. comm.); JAR-W is likely protected somewhat from these temperature spikes by the cooler upwelled waters. Kiritimati, on the other hand, also experiences equatorial nutrient upwelling but is inhabited (DeMartini et al. 2008), and the corals here are primarily losing ground to algae. Similarly, on the oligotrophic (i.e. non-upwelling, low nutrient) islands of Kingman and Teraina, we found that on the reefs surrounding the inhabited island of Teraina the corals were losing to the turfs more often than not, while on the reefs surrounding the uninhabited island of Kingman, the corals were winning more often than not. The common thread that appears to influence the outcome of coral-algal competition on both nutrient-rich and oligotrophic islands is human habitation. Fishing pressure is high on many of the inhabited reefs, which has resulted in major shifts in the reef fish and benthic community structure (DeMartini et al. 2008, Dinsdale et al. 2008, Sandin et al. 2008, Ruttenberg et al. 2011), and this may be a primary cause behind the differences between coral-algal competition outcomes.

Future work will require following coral-algal interactions at different sites over time in order to determine whether the instantaneous observations described here are consistent through time or are indicative of long-term outcomes (i.e. increases or decreases in coral cover). Factors such as the seasonal variability of algal and coral growth and reproduction could not be taken into account in this study given the remote nature and limited access to these islands. The morphology of different coral species 
should be recorded in future studies, since this feature may influence the importance of algal competition. For example, it is possible that some coral species grow above the benthos faster than their basal edges get overgrown by algae (e.g. branching or plating growth forms), while others may be restricted in their upward growth (e.g. encrusting growth forms), making success in algal competition more important for colony survival.

\section{Turf algae and CCA as indicators of coral reef health}

The dynamics of coral interactions with turf algae could be indicative of a reef's future development. Both TAB-W and KIR-S, for example, had high coral cover, but corals at those sites were losing to turf algae more than they were winning. In contrast, JAR$\mathrm{N}$ had low coral cover but corals there were winning more often against turf algae. It is possible that the reefs we observed that surrounded inhabited islands could be transitioning from the current coral-dominated state to one dominated by turf algae. An analysis of similar surveys that were conducted on reefs surrounding the inhabited Caribbean island of Curacao (Barott et al. 2012) showed that turf algae were winning more than losing against corals at each of the 8 sites surveyed, supporting the hypothesis that human habitation plays a role in coral-algal competitive dynamics. Furthermore, these data indicate that corals are losing ground to turf algae on Curacaoan reefs, which have seen a decline in coral cover over the last several decades (Bak et al. 2005). Coral reefs in the Line Islands are remote and far removed from the main population centers of the world, yet our work here shows how human activities like subsistence fishing can affect the dynamics of coral-algal interactions, which may be important for the longterm stability of the coral reef ecosystem as a whole.

Acknowledgements. This expedition would not have been possible without the support of the captain and crew of the MY 'Hanse Explorer.' Many thanks to N. Price for field assistance and to B. Zgliczynski for managing the logistics of the research cruise. We owe our great appreciation to Gina Spidel for helping us get home from Kiritimati following several unforeseen hurdles. A Special Use Permit from the US Fish and Wildlife Service was obtained for research on Kingman and Jarvis, part of the Pacific Remote Islands Marine National Monument. We also thank the NOAA Coral Reef Ecosystem Division for providing benthic cover data for Jarvis-N. This work was supported by a National Science Foundation grant to F.L.R. (OCE-0927415). K.L.B. was supported by an Achievement Rewards for College Scientists Fellowship.

\section{LITERATURE CITED}

Anthony KRN, Kline DI, Diaz-Pulido G, Dove S, HoeghGuldberg O (2008) Ocean acidification causes bleaching and productivity loss in coral reef builders. Proc Natl Acad Sci USA 105:17442-17446

Arnold SN, Steneck RS, Mumby PJ (2010) Running the gauntlet: inhibitory effects of algal turfs on the processes of coral recruitment. Mar Ecol Prog Ser 414:91-105

> Babcock RC (1991) Comparative demography of three species of scleractinian corals using age- and size-dependent classifications. Ecol Monogr 61:225-244

$>$ Bak RPM, Nieuwland G, Meesters EH (2005) Coral reef crisis in deep and shallow reefs: 30 years of constancy and change in reefs of Curacao and Bonaire. Coral Reefs 24: 475-479

Barott K, Smith J, Dinsdale EA, Hatay M, Sandin S, Rohwer F (2009) Hyperspectral and physiological analyses of coral-algal interactions. PLoS ONE 4:e8043

Barott KL, Rodriguez-Mueller B, Youle M, Marhaver KL, Vermeij MJA, Smith JE, Rohwer FL (2012) Microbial to reef scale interactions between the reef-building coral Montastraea annularis and benthic algae. Proc R Soc Lond B Biol Sci 279:1655-1664

Birrell CL, McCook LJ, Willis BL (2005) Effects of algal turfs and sediment on coral settlement. Mar Pollut Bull 51: 408-414

Birrell CL, McCook LJ, Willis BL, Diaz-Pulido GA (2008) Effects of benthic algae on the replenishment of corals and the implications for the resilience of coral reefs. Oceanogr Mar Biol Annu Rev 46:25-64

Brainard R, Maragos J, Schroeder R, Kenyon J and others (2005) The state of coral reef ecosystems of the U.S. Pacific Remote Island Areas. In: Waddell JE (ed) The state of coral reef ecosystems of the United States and Pacific Freely Associated States: 2005. Tech Memo NOS NCCOS 11. NOAA/NCCOS Center for Coastal Monitoring and Assessment's Biogeography Team, Silver Spring, MD, p 338-372

> Burkepile DE, Hay ME (2006) Herbivore vs. nutrient control or marine primary producers: context-dependent effects. Ecology 87:3128-3139

> Burkepile DE, Hay ME (2008) Herbivore species richness and feeding complementarity affect community structure and function on a coral reef. Proc Natl Acad Sci USA 105: 16201-13206

Burkepile DE, Hay ME (2009) Nutrient versus herbivore control of macroalgal community development and coral growth on a Caribbean reef. Mar Ecol Prog Ser 389: 71-84

Chadwick NE, Morrow KM (2011) Competition among sessile organisms on coral reefs. In: Dubinsky Z, Stambler N (eds) Coral reefs: an ecosystem in transition. Springer Netherlands, Dordrecht, p 347-371

De Ruyter van Steveninck ED, Van Mulekom LL, Breeman AM (1988) Growth inhibition of Lobophora variegata (Lamouroux) Womersley by scleractinian corals. J Exp Mar Biol Ecol 115:169-178

> DeMartini EE, Friedlander AM, Sandin SA, Sala E (2008) Differences in fish-assemblage structure between fished and unfished atolls in the northern Line Islands, central Pacific. Mar Ecol Prog Ser 365:199-215

Diaz Pulido G, Gouezo M, Tilbrook B, Dove S, Anthony KRN (2011) High $\mathrm{CO}_{2}$ enhances the competitive strength of 
seaweeds over corals. Ecol Lett 14:156-162

Dinsdale EA, Pantos O, Smriga S, Edwards RA and others (2008) Microbial ecology of four coral atolls in the Northern Line Islands. PLoS ONE 3:e1584

Foster NL, Box SJ, Mumby PJ (2008) Competitive effects of macroalgae on the fecundity of the reef-building coral Montastraea annularis. Mar Ecol Prog Ser 367:143-152

$>$ Gove JM, Merrifield MA, Brainard RE (2006) Temporal variability of current-driven upwelling at Jarvis Island. J Geophys Res 111:D08S07 doi:10.1029/2005JD006021

> Gross EM (2003) Allelopathy of aquatic autotrophs. Crit Rev Plant Sci 22:313-339

> Haas A, el-Zibdah M, Wild C (2010) Seasonal monitoring of coral-algae interactions in fringing reefs of the Gulf of Aqaba, Northern Red Sea. Coral Reefs 29:93-103

> Haas AF, Nelson CE, Wegley Kelly L, Carlson CA and others (2011) Effects of coral reef benthic primary producers on dissolved organic carbon and microbial activity. PLoS ONE 6:e27973

Hoegh-Guldberg O (1999) Climate change, coral bleaching and the future of the world's coral reefs. Mar Freshw Res 50:839-866

> Houlbrèque F, Ferrier-Pagès C (2009) Heterotrophy in tropical scleractinian corals. Biol Rev Camb Philos Soc 84: $1-17$

> Hughes TP (1994) Catastrophes, phase shifts, and largescale degradation of a Caribbean coral reef. Science 265: $1547-1551$

> Hughes TP, Rodrigues MJ, Bellwood DR, Ceccarelli D and others (2007) Phase shifts, herbivory, and the resilience of coral reefs to climate change. Curr Biol 17:360-365

> Jackson JBC (1977) Competition on marine hard substrata: the adaptive significance of solitary and colonial strategies. Am Nat 111:743-767

> Jompa J, McCook LJ (2002) The effects of nutrients and herbivory on competition between a hard coral (Porites cylindrica) and a brown alga (Lobophora variegata). Limnol Oceanogr 47:527-534

Lang JC, Chornesky EA (1990) Competition between scleractinian reef corals: a review of mechanisms and effects. In: Dubinsky Z (ed) Ecosystems of the world, 25. Coral reefs. Elsevier Science, Amsterdam, p 209-252

Littler MM, Littler DS, Brooks BL (2006) Harmful algae on tropical coral reefs: bottom-up eutrophication and topdown herbivory. Harmful Algae 5:565-585

McCook LJ (1999) Macroalgae, nutrients and phase shifts on coral reefs: scientific issues and management consequences for the Great Barrier Reef. Coral Reefs 18: 357-367

McCook L (2001) Competition between corals and algal turfs along a gradient of terrestrial influence in the nearshore central Great Barrier Reef. Coral Reefs 19: 419-425

Meesters EH, Wesseling I, Bak RPM (1996) Partial mortality in three species of reef-building corals and the relation with colony morphology. Bull Mar Sci 58:838-852

Miller MW (1998) Coral/seaweed competition and the control of reef community structure within and between latitudes. Oceanogr Mar Biol Annu Rev 36:65-96

Miller J, Maragos J, Brainard R, Asher J and others (2008) The state of coral reef ecosystems of the Pacific Remote Island Areas. In: Waddell JE, Clarke AM (eds) The state of coral reef ecosystems of the United States and Pacific Freely Associated States: 2008. Tech Memo NOS
NCCOS 73. NOAA/NCCOS Center for Coastal Monitoring and Assessment's Biogeography Team, Silver Spring, MD, 354-386

> Morse DE, Hooker N, Morse ANC, Jensen RA (1988) Control of larval metamorphosis and recruitment in sympatric agariciid corals. J Exp Mar Biol Ecol 116:193-217

> Negri AP, Webster NS, Hill RT, Heyward AJ (2001) Metamorphosis of broadcast spawning corals in response to bacteria isolated from crustose algae. Mar Ecol Prog Ser 223:121-131

> Nugues MM, Bak RPM (2006) Differential competitive abilities between Caribbean coral species and a brown alga: a year of experiments and a long-term perspective. Mar Ecol Prog Ser 315:75-86

> Paul VJ, Kuffner IB, Walters LJ, Ritson-Williams R, Beach KS, Becerro MA (2011) Chemically mediated interactions between macroalgae Dictyota spp. and multiple life-history stages of the coral Porites astreoides. Mar Ecol Prog Ser 426:161-170

Preskitt LB, Vroom PS, Smith CM (2004) A rapid ecological assessment (REA) quantitative survey method for benthic algae using photoquadrats with scuba. Pac Sci 58: 201-209

Price N (2010) Habitat selection, facilitation, and biotic settlement cues affect distribution and performance of coral recruits in French Polynesia. Oecologia 163:747-758

R Development Core Team (2010) R: a language and environment for statistical computing. R Foundation for Statistical Computing, Vienna

> Rasher DB, Hay ME (2010) Chemically rich seaweeds poison corals when not controlled by herbivores. Proc Natl Acad Sci USA 107:9683-9688

> Rasher DB, Stout EP, Engel S, Kubanek J, Hay ME (2011) Macroalgal terpenes function as allelopathic agents against reef corals. Proc Natl Acad Sci USA 108: 17726-17731

River GF, Edmunds PJ (2001) Mechanisms of interaction between macroalgae and scleractinians on a coral reef in Jamaica. J Exp Mar Biol Ecol 261:159-172

> Ruttenberg BI, Hamilton SL, Walsh SM, Donovan MK and others (2011) Predator-induced demographic shifts in coral reef fish assemblages. PLoS ONE 6:e21062

Sandin SA, McNamara DE (2012) Spatial dynamics of benthic competition on coral reefs. Oecologia 168: 1079-1090

Sandin SA, Smith JE, DeMartini EE, Dinsdale EA and others (2008) Baselines and degradation of coral reefs in the northern Line Islands. PLoS ONE 3:e1548

> Smith JE, Shaw M, Edwards RA, Obura D and others (2006) Indirect effects of algae on coral: algae-mediated, microbe-induced coral mortality. Ecol Lett 9:835-845

> Soong K (1993) Colony size as a species character in massive reef corals. Coral Reefs 12:77-83

Soong K, Lang JC (1992) Reproductive integration in reef corals. Biol Bull (Woods Hole) 183:418-431

> Sotka EE, Hay ME (2009) Effects of herbivores, nutrient enrichment, and their interactions on macroalgal proliferation and coral growth. Coral Reefs 28:555-568

> Tanner JE (1997) Interspecific competition reduces fitness in scleractinian corals. J Exp Mar Biol Ecol 214:19-34

Titlyanov EA, Yakovleva IM, Titlyanova TV (2007) Interaction between benthic algae (Lyngbya bouillonii, Dictyota dichotoma) and scleractinian coral Porites lutea in direct contact. J Exp Mar Biol Ecol 342:282-291 
Vermeij MJA, Smith JE, Smith CM, Vega Thurber R, Sandin SA (2009) Survival and settlement success of coral planulae: independent and synergistic effects of macroalgae and microbes. Oecologia 159:325-336

> Vermeij MJA, van Moorselaar I, Engelhard S, Hörnlein C, Vonk SM, Visser PM (2010) The effects of nutrient enrichment and herbivore abundance on the ability of turf algae to overgrow coral in the Caribbean. PLoS ONE 5:e14312

Vermeij MJA, Dailer ML, Smith CM (2011) Crustose coralline algae can suppress macroalgal growth and

Editorial responsibility: Peter Edmunds,

Northridge, California, USA recruitment on Hawaiian coral reefs. Mar Ecol Prog Ser 422:1-7

Williams I, Richards B, Sandin SA, Baum J and others (2011) Differences in reef fish assemblages between populated and remote reefs spanning multiple archipelagos across the Central and Western Pacific. J Mar Biol 2011:826234

Yellowlees D, Rees TAV, Leggat W (2008) Metabolic interactions between algal symbionts and invertebrate hosts. Plant Cell Environ 31:679-694

Submitted: April 10, 2012; Accepted: June 12, 2012 Proofs received from author(s): July 16, 2012 